\title{
Enhancing Conventional Rehabilitation Monitoring in South Africa by Adding Landscape Function Characteristics
}

\author{
A.S.H. Haagner School for Environmental Science and Development, North-West University, South Africa \\ K. Kellner School for Environmental Science and Development, North-West University, South Africa \\ D.J. Tongway Fenner School of Environment and Society, The Australian National University, Australia
}

\begin{abstract}
South African legislation requires mines to address all residual pollutant impacts and to initiate an end landuse that conforms to the concept of sustainable development, before they can be considered for closure. The conventional vegetation for gold tailings in South Africa involves grass planting into ameliorated tailings, and is primarily used for dust control and stabilization. This herbaceous layer has only recently received focus as an asset for closure and sustainable land-use. In addition, the conventional criteria used to demonstrate erosion control and persistence by this vegetation on gold tailings, such as grass basal cover and species number, may also be insufficient for closure purposes. Landscape function analysis (LFA) is a means of assessing the functionality of rehabilitated sites in terms of their ability to retain mobile resources, and relies upon measures of substrate stability, infiltration and nutrient cycling. LFA may complement or replace conventional vegetation sampling for species and composition. LFA indices are considered to reliably represent the ecological status of a rehabilitated site as they include measures of ecosystem function. We used LFA to assess the sustainability of vegetation on a chronosequence of rehabilitation sites at two gold tailings storage facilities. The surveys were conducted over two growth seasons to determine the temporal and spatial resource availability patterns, linked to seasonal changes in vegetation structure, function and composition. Sample sites were characterized on a continuum from least to most functional landscapes, and compared in terms of vegetation cover, species composition and substrate properties. The indices of landscape function were consistent across the continuum, as was landscape organization, an index of the leakiness of a landscape. Results showed that it was still too early for LFA or vegetation monitoring to predict rehabilitation trajectories, but did show that rehabilitation progress in even the oldest sites was still in its very early stages. The main limiting functionality indices were nutrient cycling and infiltration, both which required greater litter deposition and biological activity to enhance function. This was supported by litter and perennial vegetation cover being most significant in separating the more functional from less functional sites. There were no clear relationships between rehabilitation age, landscape function and plant community development, with both techniques showing the rehabilitation to be in early successional stages. LFA, in combination with vegetation monitoring, has the potential to anticipate landscape deterioration at an early stage on tailings, and to guide the most effective ameliorative actions. Although LFA is not widely used as a tool for monitoring rehabilitation of tailings in South Africa, this project illustrates that it does hold potential for assessing the functionality of rehabilitation for closure purposes.
\end{abstract}

\section{Introduction}

Planning for closure is a progressive attitude to managing the life cycle of a mine. Closure is the final stage that represents the culmination of much capital outlay and robust environmental planning, especially regarding the future of rehabilitated sites. Meticulous records detailing the past performance and short-term trajectories are essential for presenting data and results to the authorities in order to strengthen the case for closure (COCHILCO, 2002). Although rehabilitation goals may take many decades or centuries to achieve, relevant monitoring data can prove resilience in coping with environmental limitations and stochastic disturbances (De Angelis et al., 1989). On many gold tailings storage facilities (TSF) in South Africa, the steep slopes almost preclude self-sustaining herbaceous vegetation (van Wyk, 2002). For the successful revegetation of mine discard to become a reality, there needs to be a change in TSF design, construction and rehabilitation practices (Barnhisel and Hower, 1997). Therefore, to achieve closure, South African mines 
need to consider shaping TSF to correspond to local topography (van Wyk, 2002), and modifying rehabilitation practices. Without drastic changes in the way that TSF are constructed and managed, the required functional vegetation, and thus closure, is unlikely to be achieved.

The aim of this study was to evaluate the use of two monitoring techniques on a chronosequence of rehabilitating sites on the Chemwes TSF complex, in Stilfontein district, South Africa.

\section{Monitoring rehabilitation progress}

In South Africa, legislation requires that mining companies address residual pollutant impacts on the environment and that an end land-use conforms to principles of sustainable development before their sites can be considered for closure (Minerals and Petroleum Resources Development Act 28 of 2002). Conventionally in South Africa, a mixture of alien and native pasture grasses are sown in the ameliorated tailings or topsoil covers to act as a stabilization and dust suppression system (Chamber of Mines, 2007). A recent industry guideline suggests that this type of herbaceous layer will be adequate for TSF closure (Chamber of Mines, 2007), which implies that the pasture grass layer should be able to drive the ecological processes that govern the availability of ecosystem goods and services (Bell, 2001; Aronson et al., 2006). These goods and services are crucial for perpetuating ecosystems in which there are sufficiently organized biotic components to maintain ecosystem development (Aronson and Le Floc'h, 1996). Conventional criteria for determining that grassing contractual obligations have been met on South African mine tailings in general have focused mostly on investigations of basal cover and species number. This was largely due to the requirement that dust control by a grass sward must be demonstrated at contract handover. The country's highest concentration of mines is clustered within the Highveld grasslands, of which only $2.2 \%$ is formally conserved (Mucina and Rutherford, 2006). Mining and its associated activities pose a threat to the remaining tracts of non-transformed grasslands (O'Connor and Kuyler, 2006). Not all mined land has the biogeochemical potential to be restored, but regenerating some level of ecosystem function can be valuable in terms of providing goods and services.

The monitoring of pasture species attributes is however considered insufficient for establishing ecosystem development or indicating changes in landscape function (Herrick et al., 2006). Adding aspects of landscape function to the monitoring regime allows for the conventional monitoring methods of basal cover and species abundance to be supplemented by more informative techniques. One such technique is that of LFA (Tongway et al., 1997), a method developed in Australian rangelands that has shown good application in investigating the recovery of revegetated post-mining landscapes.

\section{Methodology}

The objectives of the study were to:

- Investigate the changes in species composition and diversity of herbaceous vegetation on a chronosequence of different gold tailings landscapes (i.e. both on slopes and flats).

- Investigate spatial and temporal differences in landscape organization, landscape stability, infiltration rates and nutrient cycling status on the same sites by making use of LFA.

- Integrate the various monitoring data to report on the state and future condition of rehabilitated sites.

\subsection{Site description and tailings storage facility substrata}

The study site was situated at the edge of the Stilfontein town, approximately $180 \mathrm{~km}$ southwest of Johannesburg. The mean annual precipitation was $565 \mathrm{~mm}$, but the two growing seasons in this study received vastly different rainfall amounts. The 2006/2007 growing season received only $340 \mathrm{~mm}$, $40 \%$ below the long-term average, whilst the 2007/2008 growing season received $642 \mathrm{~mm}, 12 \%$ above average. The study site comprised a complex of uncapped, fine gold TSF in various stages of reprocessing or rehabilitation, relatively undisturbed grasslands, and a spillage site where tailings sludge covered 78 ha of unmined grassland. The TSF were constructed with $35^{\circ}$ slopes of varying length. The TSF were divided into distinct substrata (Figure 1) on the basis of their aspect, parent material, age after rehabilitation (4-13 years) and ameliorative actions. The 68 year old starter walls, comprising a mixture of the original soil and slimes, 
were also surveyed to serve as potential analogue sites, as well as the relatively undisturbed grasslands surrounding the TSF.

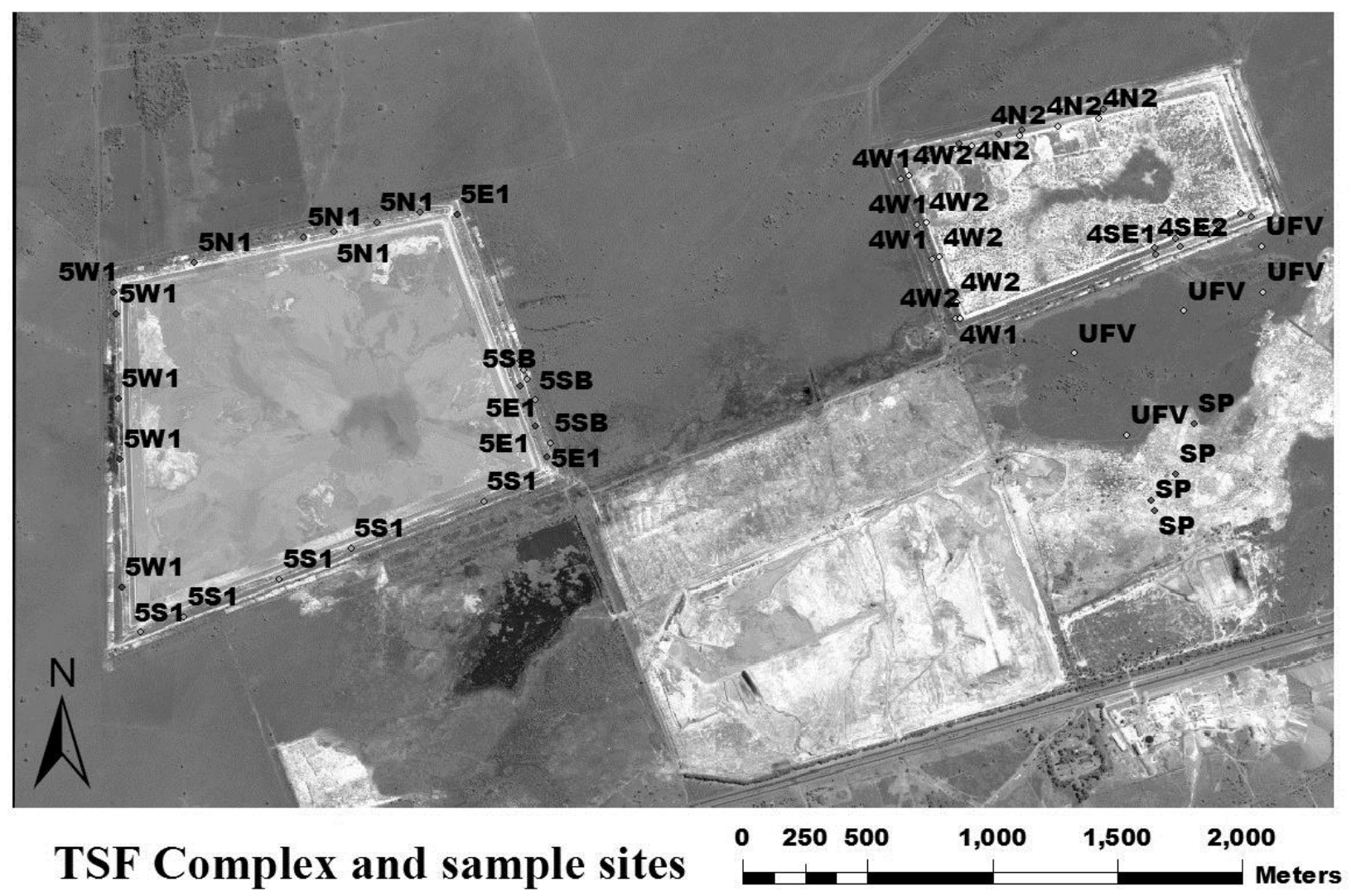

Figure 1 Quickbird ${ }^{\mathrm{TM}}$ image of the Chemwes tailings storage facility complex showing the relative position and layout of sample sites. Key for site names: 4N1=Dam 4, lower northern slope; 4N2=Dam 4, upper northern slope; 4SE1=Dam 4, lower south-eastern slope; 4SE2=Dam 4, upper south-eastern slope; 4W1=Dam 4, lower western slope; 4W2=Dam 4, upper western slope; 5N1=Dam 5, lower northern slope; 5E1=Dam 5, lower eastern slope; 5S1=Dam 5, lower southern slope; $5 \mathrm{~W} 1=$ Dam 5, lower western slope; $5 \mathrm{SB}=$ starter wall of Dam 5; $\mathrm{SP}=$ spillage area; $\mathrm{UFV}=$ undisturbed grassland sites

The primary differentiation between substrata was based on origin of parent material, thus separating the two TSFs (Dam 4 and Dam 5) from one another, as well as from the spillage site, the undisturbed grassland and the starter walls. The second level of differentiation was within each TSF, with aspect as the main distinguishing factor. Other distinguishing factors were discounted as similar management actions (chemical amelioration, composting, seeding) were undertaken throughout, and the rehabilitation efforts were completed within a year of one another. The sites (Figure 1) therefore consisted of the north (5N1), south (5S1), east (5E1) and west (5W1) slopes of Dam 5, the north (4N1 and 4N2), west (4W1 and 4W2) and southeast (4SE1 and 4SE2) slopes of Dam 4 (but at two different levels that each correspond to original parent material), the spillage site (SP), the relatively undisturbed grassland (UFV), and the starter wall (5SB) of Dam 5. The starter wall and the grassland were included in the study, as no suitable analogue sites exist for the tailings complex. The TSF are unlike any natural geographic features in the surrounding environment. This is why a compromise of an intact and undisturbed flat grassland site, and a naturally-colonised 68 year old starter wall at $35^{\circ}$ (analogous to the slope of the TSF) were selected to serve as points of departure, if rather imprecise references. We considered that actual values from landscapes with quantifiable function and species compositions would serve better than no reference at all. 


\subsection{Herbaceous layer monitoring}

The format of monitoring herbaceous plants was modified from the frequency and presence/absence estimates of descending-point counts (Roux, 1963), to the point-centered quarter (PCQ) method (MuellerDombois and Ellenberg, 1974). PCQ is a plotless technique that uses the mean distances between plants to determine density. The method involves setting out a transect with regular points, each of which is divided into four quarters. The distance to the nearest plant in each quarter is then measured, with dimensions of basal diameter. Thus, the parameters that can be gleaned from these data are plant species composition, density, basal area (and thus dominance), and frequency. The assumptions underlying the PCQ method are that the same plant is never sampled twice, and that the distribution of plants is not regular, as in a plantation, where the density would then be overestimated.

\subsection{Landscape function analysis}

Resource availability and its spatial dynamics followed the LFA method as devised by Tongway and Hindley (2004). This method was developed to assess the functional status of landscapes through human-induced changes brought about by human settlement and its associated activities, and to monitor any subsequent recuperation.

LFA examines how well a landscape is functioning as a biophysical system, using rapidly assessed soil surface indicators. These indicators focus on soil surface processes, rather than the presence, absence or abundance of selected biota, thus making the observed information different from many other monitoring procedures. LFA is comprised of three modules: a conceptual framework, a field methodology and an interpretational framework. The basis of the field methodology is the identification and description of landscape units that accumulate resources (patches), or promote the loss of resources (inter-patches). The data outputs summarize (a) the self-organization of the landscape and (b) the soil surface condition of the patches and inter-patches recognized in the self-organization step and a weighted mean representing wholeof-site values. These are expressly designed to be used over time to detect trends and to see to what extent landscape management objectives have been met. The various indicators that are measured during the soil surface assessments (Table 1) contribute in different ways to the three indices that best describe the functioning of the landscape as a biophysical unit: stability, nutrient cycling and infiltration. An additional, structural index, the landscape organization index (LOI), was also selected as a variable as it expresses the proportion of a landscape that is covered by patches and thus its 'leakiness' (Ludwig et al., 2005).

Table 1 Indices of measurement for the soil surface assessment method, with brief objectives of each measurement

\begin{tabular}{ll}
\hline Indicator & Objective \\
\hline $\begin{array}{l}\text { Rainsplash protection } \\
\text { Perennial veg cover }\end{array}$ & $\begin{array}{l}\text { Assess how perennial vegetation cover ameliorates the effects of raindrops. } \\
\text { Litter }\end{array}$ \\
Crimate basal cover of perennial grasses and canopy cover of trees/shrubs. \\
Assess the amount, origin and degree of decomposing plant litter. \\
Erosion type and severity \\
$\begin{array}{l}\text { Assess the cover of cryptograms (algae, fungi, etc.) visible on the soil surface. } \\
\text { Soil surface roughness }\end{array}$ & Assess extent to which crust is broken, leaving loose, erodible soil material. \\
Surface nature & Assess the nature and severity of recent/current soil erosion. \\
Slake test & Assess ease with which soil is mechanically disturbed for erodible material. \\
Texture & Assess stability and structure of natural soil fragments to rapid wetting. \\
\hline
\end{tabular}




\section{$4 \quad$ Results and discussion}

\subsection{Herbaceous layer monitoring}

The vegetation monitoring was undertaken in March of 2007 and February/March of 2008. This coincided with the flowering time of most plants and aided in identification of cryptic grassland species. Four replicates per sample site were deemed sufficient, based on species-area curves drawn up from pilot data. Species data were tested for Gaussian distribution, but failed for both years' datasets (Shapiro-Wilks test, $\mathrm{P}<0.05$ ). Therefore, a non-parametric test, the Kruskal-Wallis test, was conducted with Dunn's post-hoc multiple comparison test to establish whether significant differences existed, and between which sites these occurred. The Kruskal-Wallis test revealed significant differences between median values in both datasets $(\mathrm{P}<0.05)$, although 2007 data were more variable than that of 2008. In addition, non-metric multidimensional scaling (MDS) was used to qualitatively observe the differences between sites (Figure 2).
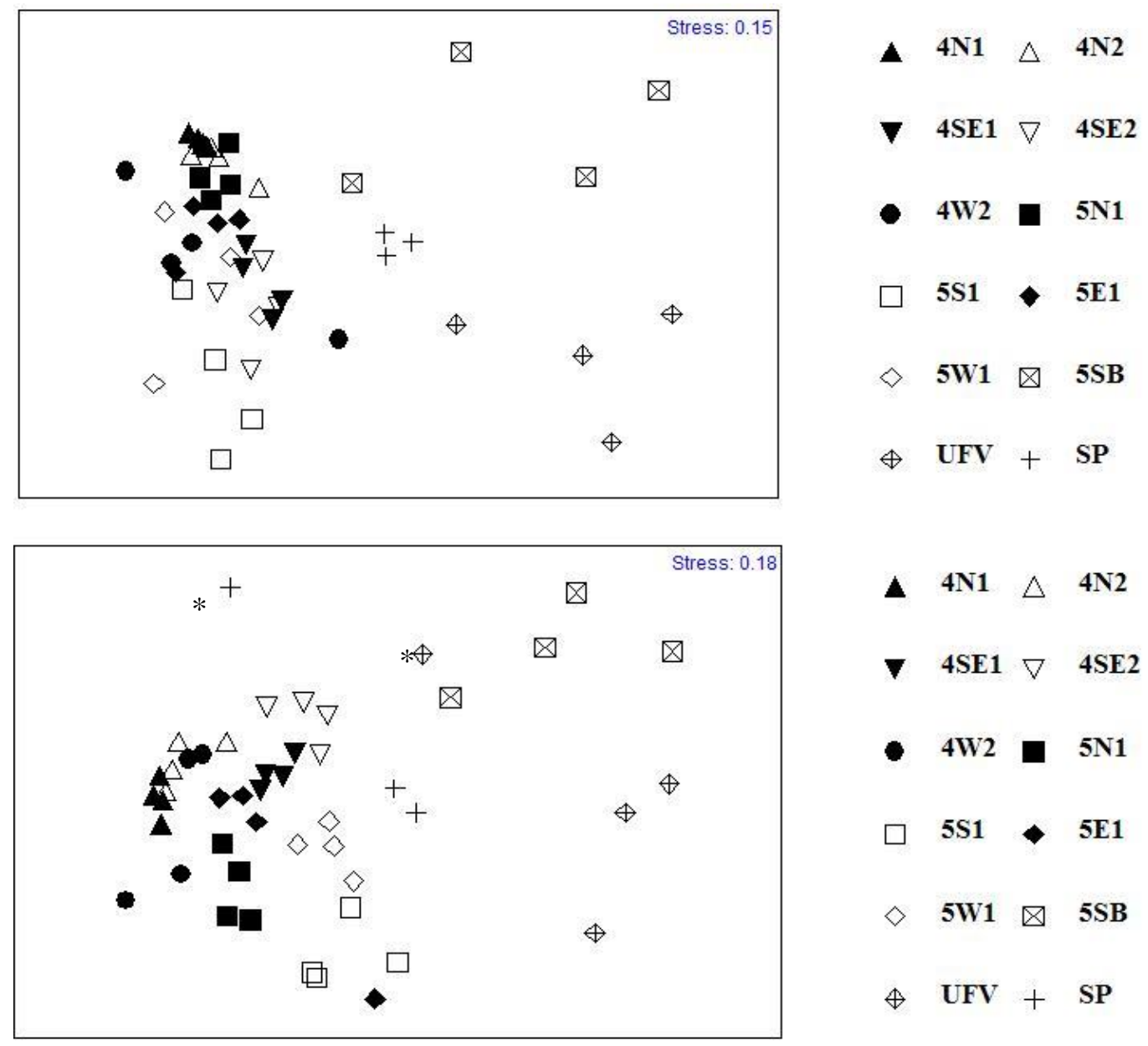

Figure 2 Non-metric multidimensional scaling graphs of the herbaceous vegetation, indicating the relative similarities between sample sites based on Bray-Curtis distance. The top figure represents data for 2007, whilst the bottom graph represents data for 2008 . Key for site names: 4N1=Dam 4, lower northern slope; 4N2=Dam 4, upper northern slope; 4SE1=Dam 4, lower south-eastern slope; 4SE2=Dam 4, upper south-eastern slope; 4W1=Dam 4, lower western slope; 4W2=Dam 4, upper western slope; 5N1=Dam 5, lower northern slope; 5E1=Dam 5, lower eastern slope; 5S1=Dam 5, lower southern slope; 5W1=Dam 5, lower western slope; $5 \mathrm{SB}=$ =starter wall of Dam 5; $\mathrm{SP}=$ spillage area; $\mathrm{UFV}=$ undisturbed grassland sites. The two sites that are marked with asterisks $(*)$ are those sites that displayed considerable differences between the two survey years and are specifically referred to in the text 
The differences largely occurred between the different substrata. None of the sites on either Dam 4 or Dam 5 differed significantly from one another, or from the SP, the UFV or the 5SB. The 5SB and UFV were quite similar in species composition and structure, but collectively only differed significantly from the SP (Figure 2).

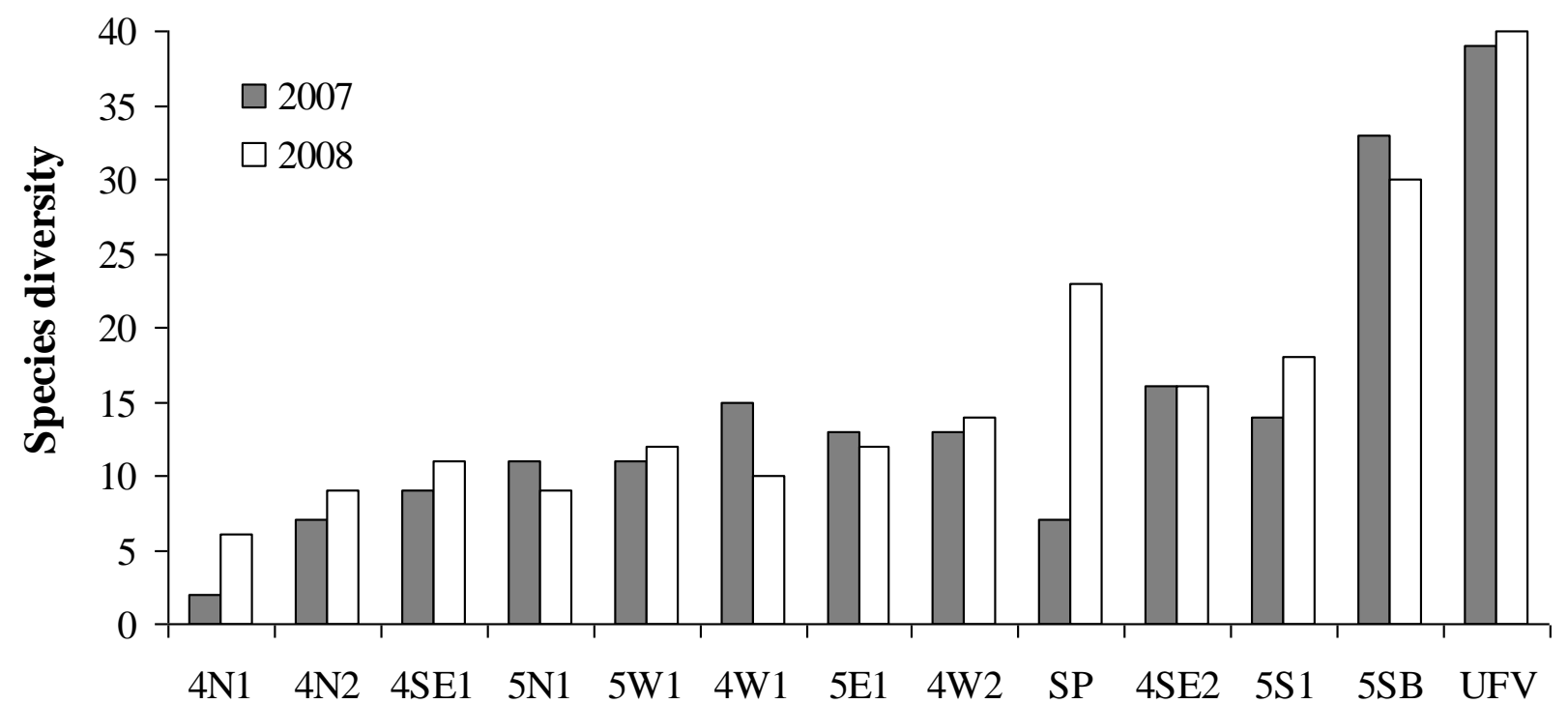

Site

Figure 3 Changes in species diversity of sample sites over the two-year period. The analogue sites are near the far right of the graph, UFV (flat grassland) and 5SB (starter wall). Key for site names: 4N1=Dam 4, lower northern slope; 4N2=Dam 4, upper northern slope; 4SE1=Dam 4, lower south-eastern slope; 4SE2=Dam 4, upper south-eastern slope; 4W1=Dam 4, lower western slope; 4W2=Dam 4, upper western slope; 5N1=Dam 5, lower northern slope; 5E1=Dam 5, lower eastern slope; 5S1=Dam 5, lower southern slope; 5W1=Dam 5, lower western slope; $5 \mathrm{SB}=$ starter wall of Dam 5; $\mathrm{SP}=$ spillage area; $\mathrm{UFV}=$ undisturbed grassland sites

Figure 2 presents the species data in terms of structure and composition using non-metric MDS. This technique uses information derived from a similarity matrix of calculated Bray-Curtis similarity values, based on raw abundance matrix data. The similarity between sites was represented by their geographic location relative to other sites. A similar pattern emerged between the two successive survey years, in which all the tailings dams' sites clustered well together, signifying low standard error margins, with no outliers. The relative distance between the main stratified units remained largely constant, but with some dynamic changes that happened within sites. These changes fell within the limits of intra-site variation, which was supported by a hierarchical cluster analysis that will not be presented here. This reflected the small changes that continuously take place within grasslands, but that do not significantly change the structure, composition and thus functional level of those sites. There are two samples within these sites that displayed considerable shift in relative position and both are marked with an asterisk in Figure 2. The first was the one SP, which underwent a drastic increase in species diversity (16 additional species in 2008) as a result of being close to the edge of the spillage where dispersal and colonization were likely less problematic than for sites further from edges. There was also an increase in the number and cover of shrubs that created microclimatic conditions for seedling establishment in this landscape where resources are constantly lost from the system. The second site that showed considerable change was one of the UFV. During 2007, it had exhibited lower diversity and lower cover values than other replicates in this group. These bare patches left vacant niches that were invaded by species in similar abundances to those found on the starter walls, thus changing its relative position to other UFV. To summarize, the vegetation data for the various sites was significantly different between the SP and most other sites, but there were few community structure-related differences over space and time. 
Figure 3 shows the changes in species diversity values across the different sample sites. Species abundance data changed very little in terms of perennial plant establishment, but the 2008 season was buoyed by an influx of annual or short-lived (ruderal) species taking advantage of the above-average seasonal rains. Four of the ten most abundant herbaceous species in 2008 were either annuals (Conyza bonariensis, Tagetes minuta, Bidens bipinnata) or short-lived forbs (Medicago sativa), compared to 2007 in which only one of the top ten was an annual species (Conyza bonariensis).

The relative abundances of perennial grasses on both Dam 4 and Dam 5 did not change significantly (analysis of variance (ANOVA), P > 0.05) without recession in the originally introduced species on either TSF. Only the abundance of the alien invasive grass species, Cortaderia jubata, which was actively eradicated during the 2007/8 season, differed over time (overall relative abundance for 2007 was 0.19 , whereas in 2008 it was 0.007$)$. The 5SB showed a slight decrease in species diversity.

The SP showed progress in species development with increases in the abundance and cover of annual and perennial herbaceous grass species, largely concentrated around existing resource accumulation points, such as trees and shrubs. However, the SP that bore no plants in the 2007 season were still bare in 2008.

Lastly, the analogue UFV remained largely unchanged, barring the influx of annual pioneers into one site that had previously had some bare soil patches.

Overall, the annual pioneers following the good 2008 rainy season were only able to invade those areas that had had the lowest species diversity and cover in 2007. There were, however, three sites that displayed deterioration of diversity values (Figure 3). These were the 5E1 (loss of eight species), the 4W1 (loss of 5 species), and the 5SB (loss of three species).

Hypothetically, those sites that exhibit levels of ecosystem development similar to the aforementioned pseudo-analogue sites in structure and diversity, should best be able to withstand invasion from unwanted pioneer species and also to maintain sustainable levels of ecological services (Andreasen et al., 2001). If this were the case, then it would suggest that those sites would also have high LFA index values, indicating that ecosystem goods and services are functioning and being maintained. However, none of the rehabilitated sites have shown that there is any trajectory towards analogue values. We did not find consistent relationships between site age, soil amelioration and the resultant plant community. Therefore our analyses, whilst allowing insight into current vegetation attributes, did not provide information on the functional attributes of the landscapes, together with how these may change over time.

\subsection{Landscape function analysis}

The LFA data collection also took place in March/April of 2007 and March of 2008. Five replicate transects were considered to be sufficient to test for variability within each site. The data were analyzed making use of the standard LFA spreadsheet package which computed the various indices of landscape function. The soil surface assessment and landscape organization indicators showed that little change had taken place during the two survey periods, but that some specific indicators were becoming more important in maintaining landscape function. Four indices were selected on the basis of their contribution to functional and structural aspects of the landscapes. These were: (1) LOI, which is an index that measures what proportion of the measured transect is covered by patches (those biophysical units that promote resource accumulation in a landscape); (2) stability index, which is made up of a combination of biological and physical indicators and that expresses a landscape's resistance to erosion and soil loss; (3) infiltration index, which is also made up of a combination of biological and physical indicators and expresses how well a landscape is able to use and accumulate water from precipitation or runoff; (4) nutrient cycling index, which is largely a biological index that indicates to what extent litter is being accumulated, broken down and incorporated into the soil matrix for pedogenesis and cycling of nutrients. Data from these indices were analyzed by first testing the means for Gaussian distribution. Unlike the vegetation data, the LFA indices did pass the Shapiro-Wilks normality test $(\mathrm{P}>0.05)$. Therefore a parametric test, the one-way ANOVA could be used to establish whether significant differences occurred between the sites. This was followed by Tukey's post-hoc test to indicate between which of the sample sites the differences, if any, occurred. The statistical analyses found significant differences only between the SP and the other sites. For LOI, the SP differed significantly from all but the least functional sites $(\mathrm{P}<0.05), 4 \mathrm{SE} 1$ and $4 \mathrm{~N} 2$. For Stability, the SP differed significantly only from the most functional sites $(\mathrm{P}<0.05)$ (Figure 5), but interestingly not from the UFV. A similar pattern emerged for 
both infiltration and nutrient cycling, in which the SP differed significantly from all sites $(\mathrm{P}<0.05)$ other than the two least functional sites, 4SE1 and 4N2.

Data were then analyzed by using Bray-Curtis distance as measure of relative similarity between sites. This allowed for the graphic illustration of similarities between sites making use of MDS (Figure 4), similar to the vegetation analyses.
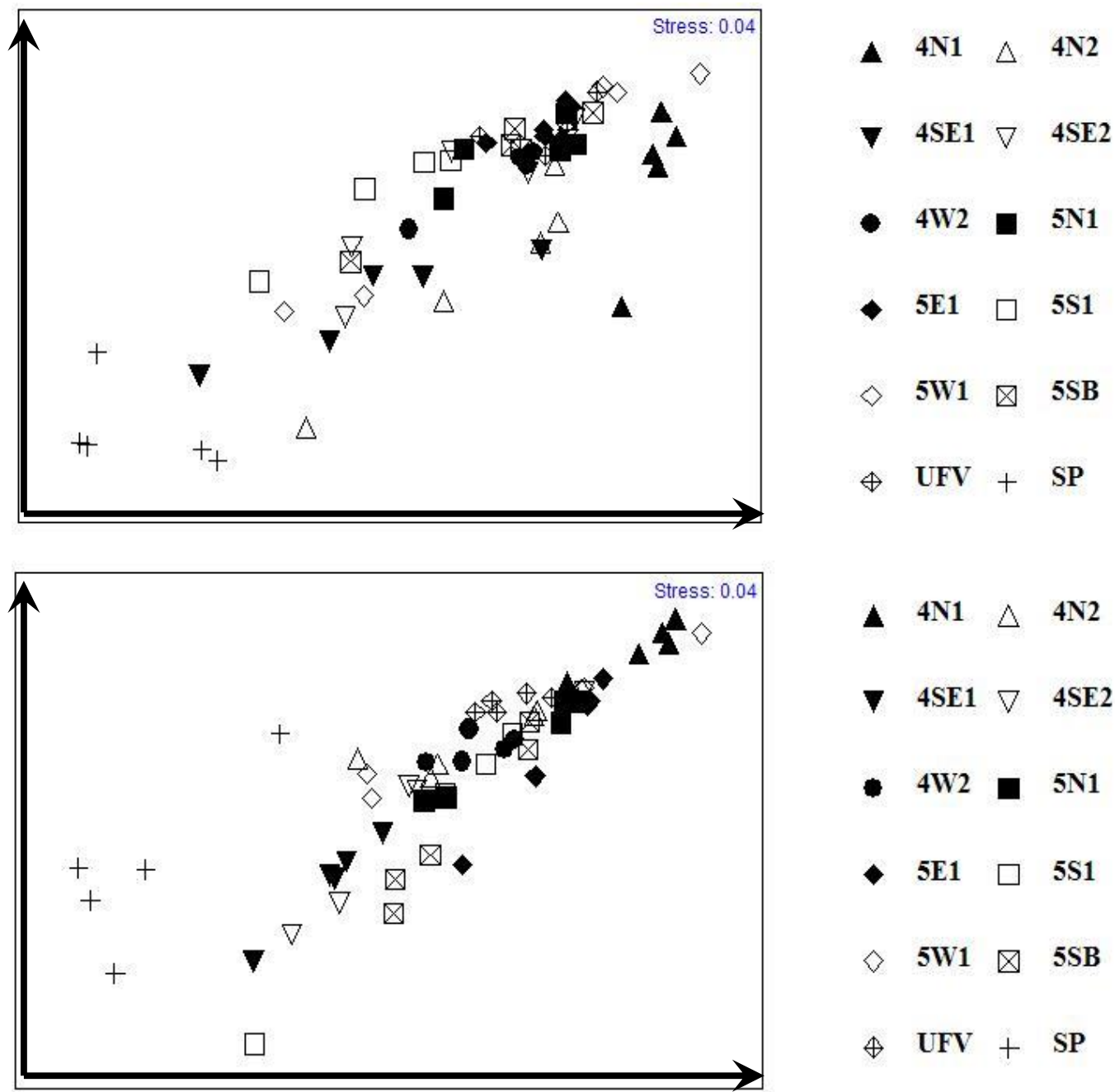

Figure 4 Non-metric multidimensional scaling graphs of the LFA indices, indicating the relative similarities between sample sites based on Bray-Curtis distance. The top figure represents data for 2007, whilst the bottom graph represents data for 2008. The arrows on the $x$-axes indicate a functionality gradient, increasing from left to right, whereas the arrows on the $y$ axes indicate an organizational gradient, increasing from bottom to top. Key for site names: 4N1=Dam 4, lower northern slope; 4N2=Dam 4, upper northern slope; 4SE1=Dam 4, lower south-eastern slope; 4SE2=Dam 4, upper south-eastern slope; 4W1=Dam 4, lower western slope; 4W2=Dam 4, upper western slope; 5N1=Dam 5, lower northern slope; 5E1=Dam 5, lower eastern slope; 5S1=Dam 5, lower southern slope; 5W1=Dam 5, lower western slope; $5 \mathrm{SB}=$ starter wall of Dam 5; $\mathrm{SP}=$ spillage area; $\mathrm{UFV}=$ undisturbed grassland sites

As in the vegetation analyses, consistent patterns emerged between the successive survey years. In both graphs of Figure 4, a functionality gradient is evident, running from left to right with the least functional sites grouping on the left of the graphs and the most functional grouping on the right. Similarly, an organizational gradient runs from bottom to top, with those sites showing least organization (not self-regulating, "leaky") at the bottom of the graph and greatest organization at the top of the graph. Most sites show similar relative positions to one another except for the SP, which increased in organization over time but not in functionality. 
In 2008, most sites displayed improved landscape organization, whilst functionality either improved or declined slightly.

Figure 5 illustrates the continuum for stability, infiltration and nutrient cycling as components of landscape function for all sample sites over the two year sampling period (2007 to 2008). The sites to the left of the graph possess the least stability, infiltration and nutrient cycling, and therefore have the greatest susceptibility to erosion as a result of poor vegetation cover. Those sites also possess the lowest infiltration scores, resulting in increased runoff volumes and thus increased net loss of resources such as topsoil, organic matter and seeds. These sites also have the lowest nutrient cycling index, a direct function of the low amount of vegetation cover, resulting in minimal litter accumulation within the soil, the formation of physical crusts, and impoverished soil biology.

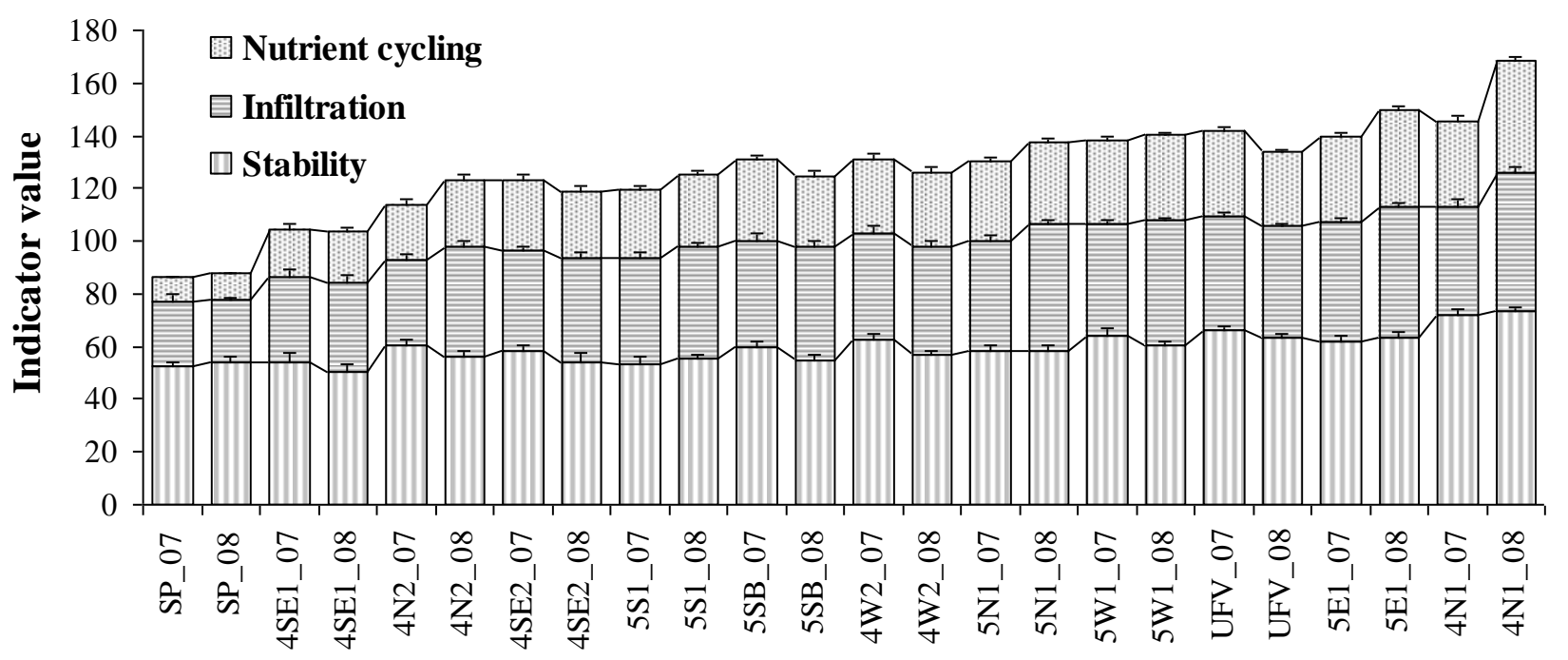

Site name

Figure 5 Changes in LFA indices (nutrient cycling, infiltration and stability) of sample sites over the two-year period (2007 and 2008). The successive survey years' data have been grouped together so that each of the adjacent pairs can be compared. Key for site names: 4N1=Dam 4, lower northern slope; 4N2=Dam 4, upper northern slope; 4SE1=Dam 4, lower southeastern slope; 4SE2=Dam 4, upper south-eastern slope; 4W1=Dam 4, lower western slope; 4W2=Dam 4, upper western slope; 5N1=Dam 5, lower northern slope; 5E1=Dam 5, lower eastern slope; 5S1=Dam 5, lower southern slope; 5W1=Dam 5, lower western slope; $5 S B=$ starter wall of Dam 5; $\mathrm{SP}=$ spillage area; $\mathrm{UFV}=$ undisturbed grassland sites

There was no obvious relationship between any of the landscape function indices and site age, indicating (as with the vegetation analyses) that the ameliorative actions were not resulting in ecosystem development linearly over time.

The indices that separated the more functional from the less functional sites were infiltration and nutrient cycling. Stability was less variable than the other indices. The indicators that contributed most to infiltration and nutrient cycling (and that were variable between sites) were litter cover and degree of litter decomposition, perennial plant cover, cryptogam cover and microtopography. These indicators, predominantly litter and perennial vegetation cover, were most different between the most and least functional sites. This indicated their importance in contributing to the ability of a site to sustain the ecological processes necessary for ecosystem persistence. Therefore, this also indicated that (1) increasing perennial vegetation cover, and (2) increasing litter deposition and breakdown, perhaps through mowing moribund swards, were key rehabilitation objectives that needed to be addressed through management actions. The achievement of (2) may involve different rehabilitation actions that accomplish more rapid succession to a perennial climax plant community, and also attain higher quality litter. 


\section{Comparisons}

Analysis of the LFA indices showed that some of the TSF sites exhibited higher values for functionality than the selected pseudo-analogue sites. It seems counter-intuitive that TSF slopes of $35^{\circ}$ can outperform undisturbed, flat, natural grassland, and that naturally recolonized slopes of similar incline to the TSF slopes, performed only as well as the semi-artificial tailings dam sites. The LFA data did not follow intuitive patterns of functionality as was observed in the vegetation analyses of the same sites. It is only when both sets of analyses are compared that the results become clear.

The TSF study sites were sown with high volumes of selected pasture seed cultivars in ameliorated tailings where they are fertilized and irrigated for up to two years (Marais et al., 2006). Some of the tailings dam sites, where $\mathrm{pH}$ neutralizing amendments, water and nutrients were supplied, now exhibit a dense sward, with very low species diversity. This is evident on especially the northern slopes of $4 \mathrm{~N} 1$ where only two species made up the entire site, and the LOI values were as high as one, indicating that the entire landscape consists of a single patch. This implies that no resources are lost from the system, which is supported by the absence of alluvial fans at the bottom of these slopes, which were always present at the bottom of the least functional landscape slopes, indicating a substantial loss of soil resources. However, sites with high landscape function did not always have the highest species diversity, but did have the greatest cover (as measured non-subjectively by LOI).

Both monitoring techniques illustrate different, but complementary aspects of current rehabilitation status and concur that all rehabilitation sites were performing much as high biomass ruderal systems. Given the relatively young age of the rehabilitation (4-13 years), this is likely as a result of the recent amelioration and management (fertilization and irrigation for the first two years). This would suggest that both techniques are necessary in order to gain a more reliable reflection of the state and rehabilitation trajectories of the tailings chronosequence. As with most monitoring techniques that assess condition of rehabilitation, both vegetation composition and LFA requires that surveys are repeated over time before final recommendations can be made. Interestingly, the results provided by LFA were more consistent during the two years of vastly different rainfall than for the vegetation monitoring.

Both monitoring techniques indicated and enumerated the differences between sites and largely gave similar verdicts as to the health of the respective substrata (with the notable exception of $4 \mathrm{~N} 1$ as discussed earlier). This may suggest that sites with high species diversity will have high functionality and vice versa, although functional groups still need to be identified. However, to test whether such a linear relationship exists, the $\log _{10}$ of cumulative values for both species diversity and landscape functionality were plotted against one another (Figure 6). The result was that sites with relatively healthy species diversity were likely to have some degree of landscape function, but that the reverse was not always true. Therefore, in the short-term, some sites have high diversity and low function, whilst other sites have low diversity and high landscape function. Although this is potentially an important finding, more long-term data is required to verify whether this is not just an artifact of short-term monitoring. 


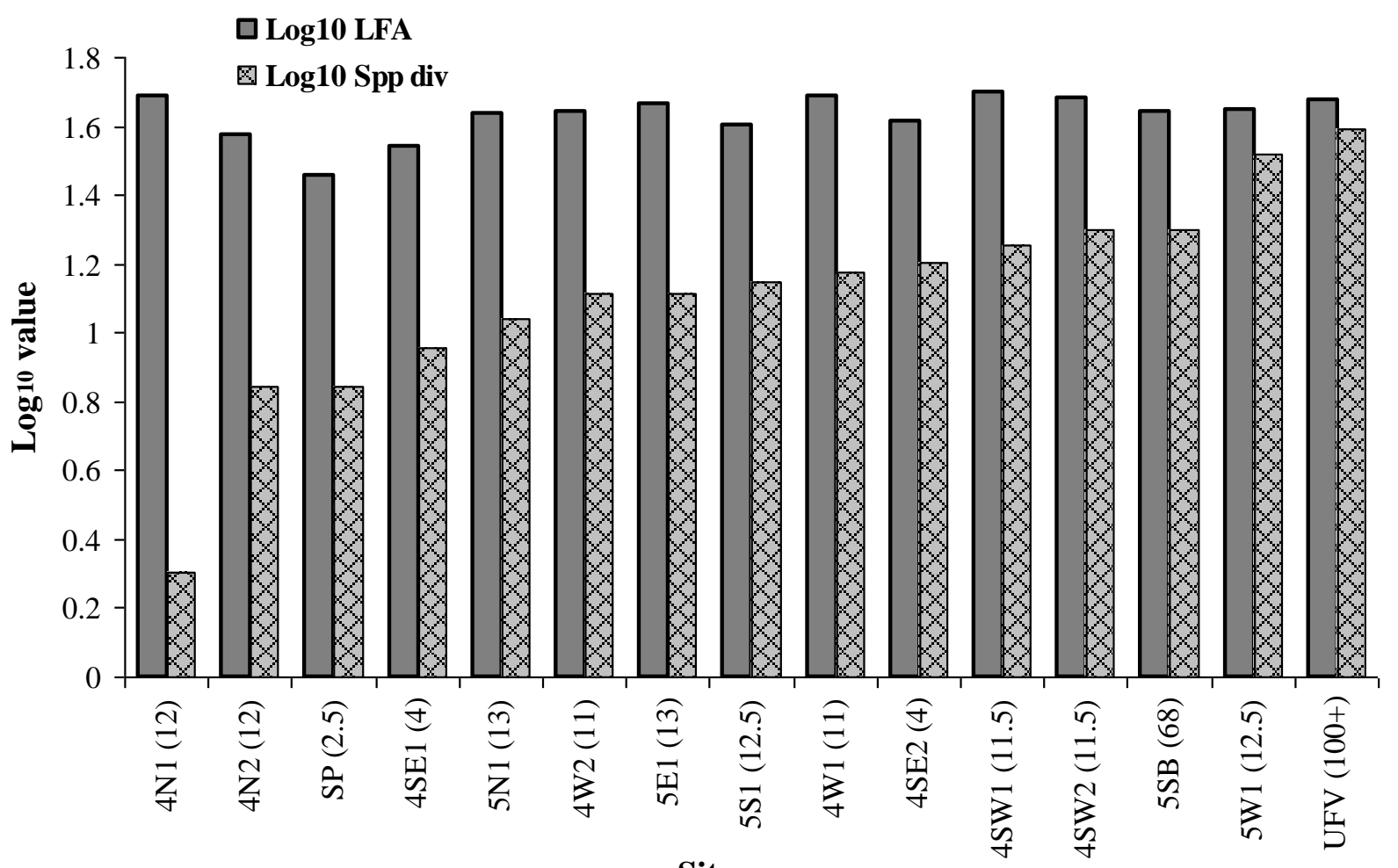

Figure $6 \log _{10}$ of the species diversity ( $\beta$-diversity) of each sampling unit, plotted against the $\log _{10}$ of the combined LFA indices. Key for site names: 4N1=Dam 4, lower northern slope; 4N2=Dam 4, upper northern slope; 4SE1=Dam 4, lower south-eastern slope; 4SE2=Dam 4, upper south-eastern slope; 4W1=Dam 4, lower western slope; 4W2=Dam 4, upper western slope; 5N1=Dam 5, lower northern slope; 5E1=Dam 5, lower eastern slope; 5S1=Dam 5, lower southern slope; 5W1=Dam 5, lower western slope; $5 \mathrm{SB}=$ starter wall of Dam 5; $\mathrm{SP}=$ =spillage area; UFV=undisturbed grassland sites. The numbers in brackets indicate site age (post-rehabilitation)

\section{Conclusions and recommendations}

The results presented here indicated that monitoring mine site rehabilitation can be a complex endeavor, with misleading results if considered only in the short-term. It is vital that the objectives of such a monitoring exercise are clearly defined before designing a monitoring strategy so that variables and indicators measured can be relevant to the end land-use objectives (Bell, 2001) as stated in closure plans (Fourie and Brent, 2006). LFA can only describe surface processes in the thin veneer of biologically active tailings material that supports these ecosystems, but we have shown that it is beneficial for the understanding of gold tailing's biogeochemical limitations for the development of a self-sustaining vegetation community.

It is unlikely that the entire gold TSF complex can be rehabilitated to an agricultural production system because the vegetation has to tolerate multiple stressors; and its resilience to disturbances caused by grazing animals, frequent burning and harvesting is thought to be low. The steep slopes are subject to high rates of runoff and erosion and the tailings material itself is only a suitable growth medium for herbaceous plants when amended. Even the periodic disturbance by researchers leaves scars in the landscape. These disturbances can substantially influence the functionality matrix (Ross et al., 2004).

Perhaps, over time, some areas, such as the spillage site in this study, may be converted to a land-use with tangible social benefits, once it receives a bill of health clean of heavy metal contamination and other residual pollutants. The unclad TSF do present a problem for attaining closure, but having the tools to acquire the right sort of data in order to plot trajectories that describe ecosystem development in terms of 
structure, function and composition can support the case for closure. To achieve this end, we advocate the use of long-term LFA repetitions combined with PCQ to monitor vegetation as the way forward for evaluating the sustainability of mine site rehabilitation for closure in South Africa.

\section{Acknowledgements}

The authors would like to express their gratitude to Fraser Alexander Tailings for funding this research, in particular to Len Reynecke and Piet van Deventer. The authors appreciate their inputs and assistance, as well as their consent to the use of data from their rehabilitation sites. The authors would also like to thank NorthWest University for providing a bursary to A. Haagner during the period of study.

\section{References}

Andreasen, J.K. and O'Neill, R.V. (2001) Considerations for the development of a terrestrial index of ecological integrity. Ecological Indicators 1, pp. 21-35.

Aronson, J. and Le Floc'h, E. (1996) Vital landscape attributes: missing tools for restoration ecology. Restoration Ecology 4, pp. 377-387.

Aronson, J., Clewell, A.F., Blignaut, J.N. and Milton, S.J. (2006) Ecological restoration: a new frontier for nature conservation and economics. Journal for Nature Conservation 14, pp. 135-139.

Barnhisel, R.I. and Rower, J.M. (1997) Coal surface mine reclamation in the Eastern United States: The revegetation of disturbed lands to hayland/pasture or cropland. Advances in Agronomy 61, pp. 233-275.

Bell, L.C. (2001) Establishment of native ecosystems after mining - Australian experience across diverse biogeographic zones. Ecological Engineering 17, pp. 377-387.

Chamber of Mines of South Africa/Coaltech (2007) Guidelines for the rehabilitation of mined land. Accessed 2 June 2008. http://www.bullion.org.za/.

Chilean Copper Commission (COHILCO) (2002) Research on mine closure policy. International Institute for Environment and Development: Mining Minerals and Sustainable Development. Accessed 2 June 2008. http://www.iied.org/mmsd/mmsd_pdfs/044_cochilco.pdf.

De Angelis, D.L., Mulholland, P.J., Palumbo, A.V., Steinman, A.D., Huston, M.A. and Elwood, J.W. (1989) Nutrient dynamics and food web stability. Annual Review of Ecological Systematics 20, pp. 71-95.

Fourie, A. and Brent, A.C. (2006) A project-based Mine Closure Model (MCM) for sustainable asset life cycle management. Journal of Cleaner Production 14(12), pp. 1085-1095.

Herrick, J.E., Schuman, G.E. and Rango, A. (2006) Monitoring ecological processes for restoration projects. Journal for Nature Conservation 14, pp. 161-171.

Ludwig, J.A., Wilcox, B.P., Breshears, D.D., Tongway, D.J. and Imeson, A.C. (2005) Vegetation patches and runofferosion as interacting ecohydrological processes in semiarid landscapes. Ecology 86, pp. 288-297.

Marais, M., van Deventer, P.W. and van Wyk, S.J. (2006) Closure of the Stilfontein Gold Mine. Proceedings of the 1st International Symposium on Mine Closure. Australian Centre for Geomechanics, Perth, Australia, pp. 261-267.

Minerals and Petroleum Resources Development Act, No. 28 of 2002 (2002) Government Gazette 26275. Government Printers, Pretoria, South Africa.

Mucina, L. and Rutherford, M.C. (eds) (2006) The Vegetation of South Africa, Lesotho and Swaziland. Strelitzia 19, South African National Biodiversity Institute, Pretoria, South Africa.

Mueller-Dombois, D. and Ellenberg, G.H. (1974) Aims and methods of vegetation ecology, John Wiley and Sons, pp. 110-115.

O'Connor, T.G. and Kuyler, P. (2006) National Grasslands Initiative: identification of compatible land-uses for maintaining biodiversity integrity. Mining Addendum. Report for SANBI's National Grasslands Biodiversity Programme. www.sanbi.org. $40 \mathrm{p}$.

Ross, K.A., Taylor, J.E., Fox, M.D. and Fox, B.J. (2004) Interaction of multiple disturbances: importance of disturbance interval in the effects of fire on rehabilitated mined areas. Journal of Austral Ecology 29(5), pp. 508-529.

Roux, P.W. (1963) The descending-point method of vegetation survey. A point sampling-method for the measurement of semi-open grassland and Karoo vegetation in South Africa. South African Journal of Agricultural Science 6, pp. 273-288.

Tongway, D.J., Hindley, N., Ludwig, J., Kearns, A. and Barnett, G. (1997) Early indicators of ecosystem rehabilitation on selected mine sites. Proceedings of the 22nd Annual Minerals Council of Australia Environmental Workshop, Adelaide, pp. 494-505. Minerals Council of Australia, Canberra, Australia.

Tongway, D.J. and Hindley, N. (2004) Landscape Function Analysis: procedures for monitoring and assessing landscapes with special reference to minesites and rangelands. CSIRO, Australia.

Van Wyk, S.J. (2002) An analytical investigation of the biophysical factors that inhibit successful ecological restoration of gold tailings dams. M.Env.Sci Thesis, North-West University. 